\title{
Artificial and Natural Aging of Polypropylene Used in Passenger Vehicle Bumpers
}

\section{HONGSHEN ZHANG*, HONGFEI ZHENG}

Kunming University of Science and Technology, Faculty of Mechanical and Electrical Engineering, No.727 South Jingming Rd., Chenggong District, Kunming, 650500, China

\begin{abstract}
Polypropylene (PP) has a wide range of applications in the automobile bumpers due to its many excellent properties. Mechanical properties of PP for automobile bumpers are investigated through an artificial accelerated aging test. The aging rules after different years of normal use and the artificial accelerated aging test are analyzed. The correlation between natural and artificially accelerated aging is also explored. It provides a reference for the study of the aging properties of polymers for automotive applications. Results show that the UV aging test can effectively simulate changes in tensile and bending strengths after natural aging and can be used to evaluate the weathering resistance of PP materials used in automotive bumpers. The tensile and bending strengths of these materials remain good during aging, and elongation is sensitive to aging. The short-term artificial accelerated aging test does not exert a significant influence on the impact strength of materials, and artificial accelerated aging does not completely reproduce the aging process of the material.
\end{abstract}

Keywords: passenger vehicle bumpers, polypropylene, mechanical properties, natural aging, artificial accelerated aging

\section{Introduction}

Bumpers are an essential component of passenger vehicles. In order to meet the needs of automotive lightweight, bumpers housings are made of plastic materials, such as polypropylene (PP). Bumpers act as a safety device that protects and decorates the car and improves the aerodynamic characteristics of the vehicle [1]. With the development of the automotive industry and the large-scale application of engineering plastics, bumpers, as important safety devices, have been subject to innovation. In addition to maintaining the original protective function of front and rear bumpers, pursuing harmony with the body shape and achieving light weight have also become crucial goals [2].

The application of plastics in automobiles has gradually expanded from interior to exterior parts. The use of numerous plastic products to replace various expensive non-ferrous metals and alloys can improve car shape and design flexibility, reduce the cost of parts processing, assembly and maintenance, and decrease the energy consumption of cars. Plastics usage has become increasingly common due to the properties of the material and the substitutability of several polymers used in automobiles [3]. The application of plastic in passenger vehicles has expanded from common decorative parts to essential parts, such as structural and functional components.

PP is one of the most popular consumer thermoplastics in the global polymer market because of its low density and cost, high heat distortion temperature, and excellent chemical and electrical resistance [4]. It is used in many fields, including household goods, automotive parts, packaging and labeling, the textile industry, and electrical and electronic fields [5-9]. PP is also widely used in the processing and design of vehicle bumpers because of its numerous excellent properties. At present, automotive bumpers are primarily made of ethylene propylene diene monomer (EPDM)-modified PP, which is light weight, and has excellent impact resistance and easy moldability. However, prolonged exposure to light, oxygen, heat and other environmental factors during use can lead to discoloration and brittleness of the plastic and degradation of mechanical properties. They ultimately become unusable, especially in outdoor applications. Therefore, determining the effects of light, heat, humidity, and other climatic stresses on

*email: hongshen@kust.edu.cn 
the properties of plastics is essential. Given the fact that the aging properties of a material are not revealed until after long-term use, artificial accelerated aging tests are adopted generally performed to simulate and strengthen the destructive effect of natural outdoor climate on specimens, and eliminate the constraints of natural aging [10-11]. Accelerated aging tests with specific laboratory light sources are often required to determine the effects of light, heat and humidity on the physico-chemical and optical properties of plastics. Exposure in laboratory facilities is conducted under more controlled conditions than those of atmospheric aging and is used to accelerate polymer degradation and product failure. The study of plastic aging is becoming increasingly important to modern industries, especially the automotive industry. Studying the aging behavior of bumpers is important for the recovery and equivalent performance reuse of typical plastic materials for decommissioned passenger vehicles.

Automotive bumpers degrade when they are used outdoors and exposed to sunlight, temperature, oxygen, water and pollutants; UV radiation and high temperatures are the main contributors to degradation [12-13]. Although UV accounts for only 5\% of sunlight, it is a major light factor in the degradation of the durability of outdoor products because the photochemical effects of sunlight increase with decreasing wavelengths and these short wavelengths cause considerable damage to PP. The energy of solar UV radiation $(\lambda<380 \mathrm{~nm})$ is high enough to break many typical bonds. Thus, reproducing the entire sunlight spectrum is unnecessary when simulating the damaging effects of sunlight on the physical properties of materials. In most cases, only short wavelengths of UV light need to be simulated. In this study, UV aging and high-temperature aging tests were performed by simulating solar radiation, temperature, humidity, and usage in natural environments.

The material to be tested is exposed to a controlled interactive cycle of sunlight and moisture while the temperature is increased. UV fluorescent lamps are used to simulate sunlight. This test can also simulate the effect of moisture through condensation or spraying. In just a few days or weeks, UV weathering tests can reproduce the damage that would otherwise take months or years outdoors. Damage includes fading, discoloration, loss of brightness, chalking, cracking, blurring, embrittlement, loss of strength and oxidation [14].

In general, short-term exposure of plastics to high temperatures releases volatile substances, such as moisture, solvents, or plasticizers; reduces molding stress; enhances thermosetting plastic curing; increases crystallinity; and causes color changes in the plasticizer. Several materials, such as PVC, may become brittle due to the loss of the plasticizer or breakage of the polymer molecular chain. PP and its copolymers become very brittle as their molecules degrade, whereas polyethylene softens and becomes fragile before its tensile strength and elongation diminish. Therefore, high-temperature test chambers must be used when studying the performance of plastics, rubber, color paints and varnishes, polymers, and other components (e.g., circuit boards) at high temperatures [15].

Song et al. tested the color, gloss, tensile strength, elongation, bending strength, and impact strength of PP and evaluated its aging properties; they performed principal component analysis to identify the property that characterizes all PP properties [16]. James et al. studied the properties of PP in weathered wood-plastic composites and found that the crystallinity of PP increases with aging time, the numberaverage and weight-average molecular weights of PP decrease with aging time, and the mechanical and rheological properties decrease [17]. Azuma et al. showed that light intensity affects the rate of degradation; in the presence of talc compounds, exposure to sunlight, xenon lamps, and metal halide lamps with high visible light intensities synergistically accelerates degradation [18].

Solar irradiation and acid rain also exert a synergistic effect on the degradation of PP and PP/ talc composites. Célia et al. compared the degradation behavior of hemp fiber-reinforced polypropylene biological composites under outdoor and artificial climatic conditions, established correlations, and found that artificial aging times are similar to outdoor aging times [19]. Colom et al. studied the degradation of PP-polyethylene copolymers after 2.5 years of natural aging and $5000 \mathrm{~h}$ of artificial aging in a xenon room and found that the samples exposed to weathering had a lighter degree of modification than the artificially aged samples [20]. 
The deterioration of plastic materials has elicited widespread concern. However, the laboratory environment cannot fully mimic the natural environment, and only a few studies have been conducted on the aging behavior of PP in normal use. In order to simulate various harsh conditions in the normal use of the product, and predict the product service life reasonably according to the requirements of use, the mechanical properties of PP materials for new automobile bumpers were tested and recorded under different aging times via UV and high-temperature aging. The correlation between artificially accelerated and natural aging was investigated by comparing the mechanical properties of PP materials after different years of normal use.

\section{Materials and methods}

\subsection{Materials}

A new bumper material was purchased from Yanfeng Visteon Automotive Trim Systems Co., Ltd. The PP+EPDM-TD10 material was a modified PP, that is, raw PP materials were added with $10 \%$ talcum powder enhancer, and another EPDM toughening agent to improve the rigidity and heat resistance of the material and reduce material shrinkage. The automotive bumper is a typical material with flame retardation and impact resistance properties. The old bumpers were recycled from Shanghai Baoshan Iron \& Steel Co., the length of service was 6, 10, 12 and 19 years. Besides, the old bumpers were made of the same material as the new bumpers.

\subsection{Preparation of composites}

The old bumpers were shot-blasted in a shot-blasting machine (by the action of centrifugal force, a projectile with a diameter of about $0.2-3 \mathrm{~mm}$ was thrown to the surface of the workpiece to remove the surface oxide skin and other impurities and thus improve the appearance of quality) to clean the surface and remove the paint. The samples were then broken up, washed in detergent to remove dirt and odor, and dried naturally until they were free of moisture. The dried samples are shown in Figure 1. In accordance with the GB/T17037.1-2019 standard, the purchased bumper material and the crushed sample were made into standard tensile, bending, and impact test samples. The samples prepared from the new bumper material were divided into two groups and tested for their mechanical properties after UV and high-temperature aging tests. The samples prepared from the old bumpers were directly tested for their mechanical properties without aging treatment. The aim was to compare bumper performance, including tensile, bending, and elongation and impact strengths, after the artificial aging of the new bumper and after normal use. The test procedure is shown in Figure 2.

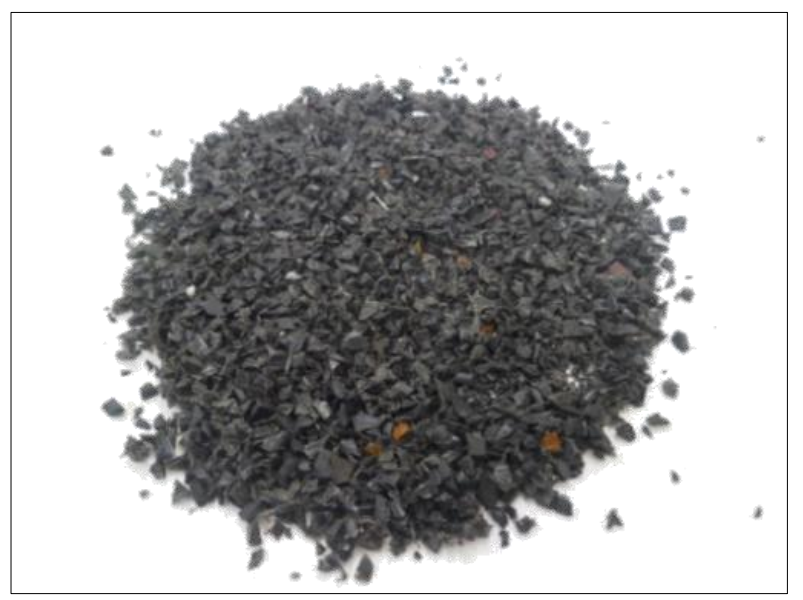

Figure 1. Dried sample 


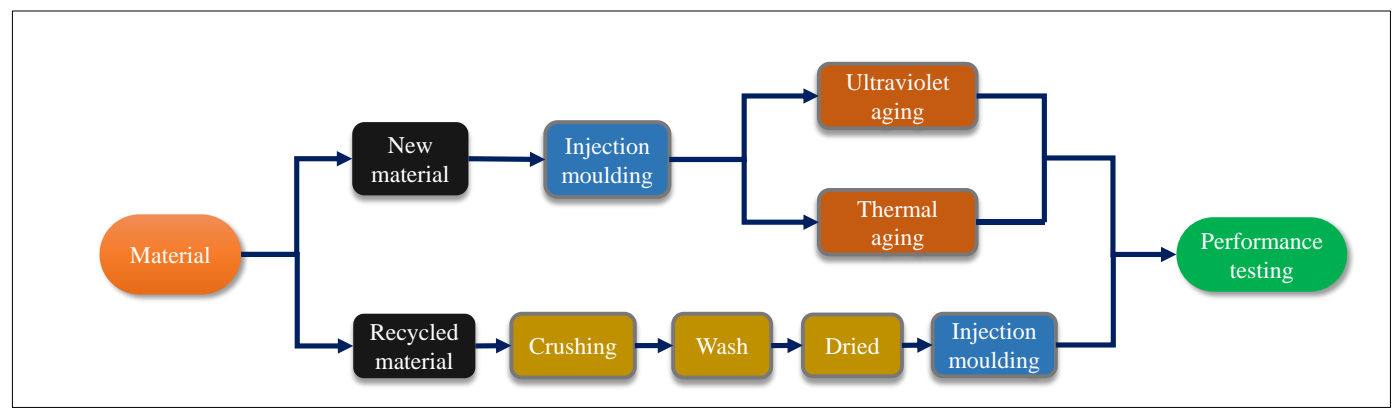

Figure 2. Experimental procedure

\subsection{Artificial aging}

Accelerated artificial weathering tests are usually performed using xenon, UV, metal halide, and carbon arc lamps [18]. UV lamps are used in UV aging test chambers because they are more stable and reproduce test results better than other lamps do. Using fluorescent UV lamps is the best way to simulate the effects of sunlight on physical properties, such as brightness loss, cracking, and peeling. UV lamps are of different types, most of which produce UV light rather than visible or infrared light. The main difference between lamps is the total amount of UV energy they produce in their respective wavelength ranges. Different lamps produce different test results. Actual exposure conditions can indicate which type of UV lamp should be used. According to GB/T14522-2008, when using a UVA-340 fluorescent UV lamp, the relative spectral energy distribution of this type of lamp should be consistent with the requirements in Table 1. That is, less than $300 \mathrm{~nm}$ of radiation accounts for less than $2 \%$ of the total radiation percentage, which is the peak radiation energy at $340 \mathrm{~nm}$ wavelength. UVA-340 produces a spectrum only at UV wavelengths found in sunlight and provides an excellent simulation of the critical shortwave wavelength range of the sunlight spectrum (i.e., 295-360 nm). The specimens in this study were exposed to periodic repetitive light and humidity or continuous light, and both light and humidity were under controlled conditions. The specimens were exposed at the specified test time.

Table 1. Relative spectral energy analysis of UVA-340 fluorescent UV lamp

\begin{tabular}{|c|c|c|}
\hline Wavelength passband / nm & Minimum value / \% & Maximum value / \% \\
\hline$\lambda<290$ & $/$ & 0.01 \\
\hline $290 \leq \lambda \leq 320$ & 5.9 & 9.3 \\
\hline $320<\lambda \leq 360$ & 60.9 & 65.5 \\
\hline $360<\lambda \leq 400$ & 26.5 & 32.8 \\
\hline
\end{tabular}

Note: The data in the table show cumulative irradiance as a percentage of the total irradiance within a given wavelength passband, which is $290-400 \mathrm{~nm}$

UV aging was performed on the first set of samples in accordance with GB/T14522-2008 by using the UVA-B UV aging test chamber, model BG/ZW-J-D, of BoGong Test Equipment Co. (Shanghai). The specimens were exposed to periodic cycles of light and humidity every $12 \mathrm{~h}$, The cycles consisted of irradiation at black standard temperature (BST) $(60 \pm 3)^{\circ} \mathrm{C}$ for $8 \mathrm{~h}$, followed by condensation at BST $(50 \pm 3)^{\circ} \mathrm{C}$ for $4 \mathrm{~h}$. The wavelength was controlled at $340 \mathrm{~nm}$, and the irradiation intensity was $0.89 \pm 0.02$ $\mathrm{W} / \mathrm{m}^{2} \times \mathrm{nm}$. The samples were collected and analyzed after $240,504,768,1000,1400$, and $1800 \mathrm{~h}$ of exposure.

According to GBT 7141-2008, a forced-ventilation-type thermal aging test chamber was used to conduct the test at a single temperature, and all specimens were exposed simultaneously in the same device. A specimen was installed on the specimen holder, and the specimen holder was placed in the heat aging test box to ensure that both sides of the specimen are exposed to airflow. The position of the 
specimen or specimen holder was adjusted periodically to minimize the impact of temperature changes in the heat aging test box. The second set of samples was placed in the high-temperature aging test chamber for the samples to undergo accelerated aging under heat and climate. The aging resistance of plastic was evaluated by determining the change in properties before and after exposure.

Thermal aging was performed by using the high-temperature aging test chamber of BoGong Test Equipment Co. (Shanghai). Its model number is BG/GWL100. The temperature of the test chamber was set to $105^{\circ} \mathrm{C}$ and the temperature fluctuation was $\pm 0.5^{\circ} \mathrm{C}$. The samples were collected and analyzed after $16,32,64,128,500,750,1200$ and 1600 hours of aging.

\subsection{Mechanical performance testing}

The effect of aging time on the performance of the samples was investigated by measuring the mechanical properties of the samples collected at each period in the aging test and the mechanical properties of the samples prepared using old bumpers of different years. The tensile strength, bending strength, bending modulus of elasticity and elongation of the sample were determined using an electronic universal tensile machine (Instron 4465, Instron Corp., USA). The impact strength of a specimen was measured using a pendulum impact tester (RAY-RAN Test Equipment Ltd., UK). Five specimens from each group were measured and averaged. The performance criteria of the new bumper at room temperature are shown in Table 2.

Table 2. New bumper performance standards at room temperature

\begin{tabular}{|c|c|c|c|}
\hline Serial number & Test items & Units & Required value of new material \\
\hline 1 & Tensile yield strength & $\mathrm{MPa}$ & $\geq 15$ \\
\hline 2 & Tensile strength & $\mathrm{MPa}$ & $\geq 15$ \\
\hline 3 & Elongation & $\%$ & $\geq 20$ \\
\hline 4 & Bending strength & $\mathrm{MPa}$ & $\geq 650$ \\
\hline 5 & Bending modulus of elasticity & $\mathrm{MPa}$ & $\geq 15$ \\
\hline 6 & Notch impact strength & $\mathrm{KJ} / \mathrm{m}^{2}$ & \\
\hline
\end{tabular}

\section{Results and discussions}

\subsection{Natural aging}

Evaluation of aging performance was carried out using the law of change in mechanical property retention rate with aging time. The mechanical property retention rate is the ratio of the mechanical properties per sample taken to the initial mechanical properties of the material. The data of each performance test on the bumper with natural aging are shown in Table 3, and the mechanical property retention rate of the sample under natural aging are presented in Figure 3. As time changed, the retention rate of tensile and bending strengths fluctuated. On the basis of the chemical reaction mechanism, the chemical reactions after the aging of polymers can be divided into two categories. The first one is the cross-linking of polymer chains. When the molecular weight of the polymer increases, a threedimensional network structure is generated, and strength is increased. The second category is polymer chain fracture, that is, the average molecular weight and strength decrease. Figure 3 demonstrated that the two types of reactions existed simultaneously in the aging process. Depending on the reaction conditions, sometimes cross-linking was dominant, and sometimes degradation was dominant [21]. During the aging process, some degradation was observed on the surface, and the aging layer was thin, which exerted minimal influence on the yield point of the specimens during tensile and bending. Therefore, the trends of the tensile yield and bending strength retention rates of all specimens were basically similar, and the decrease was small. Figure 3 showed that the retention rates of tensile and bending strengths after natural aging were close to $100 \%$. 
Table 3. Natural aging performance test

\begin{tabular}{|c|c|c|c|c|c|c|}
\hline Time & $\begin{array}{c}\text { Tensile yield } \\
\text { strength (MPa) }\end{array}$ & $\begin{array}{c}\text { Tensile strength } \\
(\mathrm{MPa})\end{array}$ & Elongation, \% & $\begin{array}{c}\text { Bending } \\
\text { strength (MPa) }\end{array}$ & $\begin{array}{c}\text { Bending } \\
\text { modulus of } \\
\text { elasticity (MPa) }\end{array}$ & $\begin{array}{c}\text { Notch impact } \\
\text { intensity } \\
\left(\mathrm{KJ} / \mathrm{m}^{2}\right)\end{array}$ \\
\hline 1994 & 17.9 & 16.0 & 483 & 24.7 & 806 & 57.4 \\
\hline 1996 & 17.2 & 13.1 & 131 & 22.5 & 772 & 32.7 \\
\hline 2001 & 18.2 & 14.9 & 32 & 24.9 & 820 & 3.44 \\
\hline 2003 & 21.0 & 15.4 & 205 & 30.4 & 1047 & 13.5 \\
\hline 2007 & 17.1 & 17.1 & 72 & 22.5 & 905 & 2.21 \\
\hline New material & 18.5 & 18.6 & 460 & 26.5 & 1189 & 35.5 \\
\hline
\end{tabular}
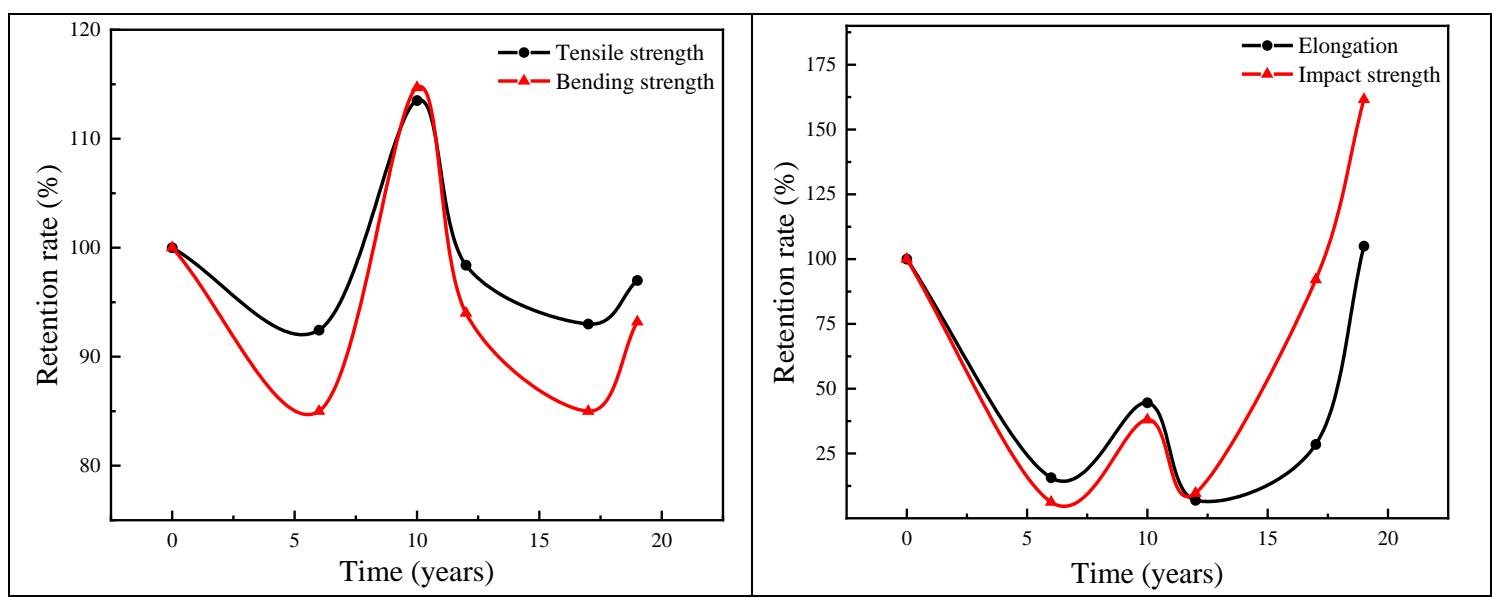

Figure 3. Retention rate of the mechanical properties of naturally aged samples

The changes in the retention rate of the elongation and impact strength of the naturally aged samples were significant. The other climatic factors of atmospheric aging, aside from sunlight, temperature, humidity, temperature difference, rainfall washout, wind pressure, and erosion, are complex. These factors affect the performance of the material and may lead to physical stress in the material. For example, temperature changes may produce thermal shock stress, and continuous rainfall washout and wind pressure may produce fatigue stress. These physical stresses can break the polymer chain, leading to changes in the molecular structure and reduced physical properties.

The environmental factors in natural aging are generally not subject to artificial control. Identification of the exact environmental factors that affect product performance through an environmental test cannot be achieved by manipulating the test conditions, such as artificially increasing the environmental temperature and humidity. Compared with the artificial accelerated aging test, the natural aging test can truly reflect the degree of environmental damage on a product in a certain area and period, but it is affected by the changes in many uncertain factors in the test conditions. Generally, the influence of natural aging varies with the differences in the natural environment (region, country, weather, and season) of the aging site. Therefore, although the materials were the same, the elongation and impact strength of the samples prepared after different years of use of the bumpers varied considerably in this study.

\subsection{Artificial aging}

The test data of the samples after UV and high-temperature aging are shown in Tables 4 and 5, respectively. The retention rate of the tensile and bending strengths of the specimen after UV and hightemperature aging is presented in Figure 4. From the Figure 4(a), it can be seen that the retention rate of the tensile and bending strengths increased initially then decreased with the increase of aging time in the UV aging test, and both reached the maximum at $768 \mathrm{~h}$. The tensile strength retention rate remained unchanged for $128 \mathrm{~h}$ after the start of the high-temperature aging test; then, it begins to increase, reached a maximum of about $107 \%$ at $500 \mathrm{~h}$, and declined afterward. In the beginning of the high-temperature aging (Figure 4(b)), the bending strength retention rate of the samples increased rapidly to $110 \%$ at 16 
$\mathrm{h}$, reached the maximum at $32 \mathrm{~h}$ (close to $113 \%$ ), remained unchanged until $500 \mathrm{~h}$, and began to decline afterward.

This result was due to the fact that PP is a crystalline polymer. The cooling of PP samples under injection molding conditions is similar to quenching, and crystallization is incomplete. Crystallization continues to deepen and be perfected in an aging environment for a certain period, leading to an increase in the crystallinity of the material. In the beginning of thermal oxygen aging, the crystallization rate is greater than the thermal oxygen degradation rate; the tensile and bending strengths of PP materials at this stage of the retention rate continue to rise. During this period, thermal oxygen degradation occurs on the surface of the materials, the degree of which is very low and still in the initiation stage. In the middle period, the deepening and perfection of the crystallization of the material are almost complete. The influence of thermal oxygen degradation on the properties of the material begins to appear gradually, and the internal part of the material enters the initiation stage of thermal oxygen degradation, which shows a slow downward trend. At the late stage, with the accumulation of alkyl radicals, peroxides, and other highly reactive intermediates in the material, the rate of thermo-oxidative degradation of PP starts to accelerate, and the degradation reaction expands to the internal depth of the material, causing decomposition and fracture of the PP macromolecular chain. As a result, the tensile and bending strengths of the material at the late stage of high-temperature aging rapidly decline [22].

Table 4. Properties of the samples after UV aging

\begin{tabular}{|c|c|c|c|c|c|c|}
\hline Aging time & $\begin{array}{c}\text { Tensile yield } \\
\text { strength } \\
(\mathrm{MPa})\end{array}$ & $\begin{array}{c}\text { Tensile strength } \\
(\mathrm{MPa})\end{array}$ & $\begin{array}{c}\text { Elongation } \\
\%\end{array}$ & $\begin{array}{c}\text { Bending } \\
\text { strength }(\mathrm{MPa})\end{array}$ & $\begin{array}{c}\text { Bending } \\
\text { modulus of } \\
\text { elasticity }(\mathrm{MPa})\end{array}$ & $\begin{array}{c}\text { Notch impact } \\
\text { intensity } \\
\left(\mathrm{KJ} / \mathrm{m}^{2}\right)\end{array}$ \\
\hline New material & 18.5 & 18.5 & 460 & 26.5 & 1189 & 35.5 \\
\hline $240 \mathrm{~h}$ & 18.8 & 18.8 & 441 & 28.3 & 1251 & 35.9 \\
\hline $504 \mathrm{~h}$ & 18.7 & 18.7 & 420 & 28.2 & 1217 & 34.4 \\
\hline $768 \mathrm{~h}$ & 19.9 & 19.9 & 96.1 & 32.0 & 1914 & 39.6 \\
\hline $1000 \mathrm{~h}$ & 19.4 & 19.4 & 263 & 29.1 & 1267 & 35.0 \\
\hline $140 \mathrm{~h}$ & 18.6 & 18.6 & 252 & 28.3 & 1210 & 33.9 \\
\hline $1800 \mathrm{~h}$ & 17.7 & 17.7 & 243 & 27.7 & 3152 & 32.7 \\
\hline
\end{tabular}

Table 5. Properties of the samples after thermal aging

\begin{tabular}{|c|c|c|c|c|c|c|}
\hline Aging time & $\begin{array}{c}\text { Tensile yield } \\
\text { strength } \\
(\mathrm{MPa})\end{array}$ & $\begin{array}{c}\text { Tensile strength } \\
(\mathrm{MPa})\end{array}$ & $\begin{array}{c}\text { Elongation } \\
\%\end{array}$ & $\begin{array}{c}\text { Bending } \\
\text { strength }(\mathrm{MPa})\end{array}$ & $\begin{array}{c}\text { Bending } \\
\text { modulus of } \\
\text { elasticity }(\mathrm{MPa})\end{array}$ & $\begin{array}{c}\text { Notch impact } \\
\text { intensity } \\
\left(\mathrm{KJ} / \mathrm{m}^{2}\right)\end{array}$ \\
\hline $16 \mathrm{~h}$ & 19.1 & 19.1 & 181 & 29.8 & 1445 & 36 \\
\hline $32 \mathrm{~h}$ & 19.0 & 19.0 & 151 & 29.8 & 1461 & 36.7 \\
\hline $64 \mathrm{~h}$ & 19.0 & 19.0 & 227 & 29.5 & 1474 & 36.2 \\
\hline $128 \mathrm{~h}$ & 18.9 & 18.9 & 179 & 29.5 & 1409 & 37.0 \\
\hline $500 \mathrm{~h}$ & 19.7 & 19.7 & 71.6 & 29.8 & 1314 & 35.5 \\
\hline $750 \mathrm{~h}$ & 19.0 & 19.0 & 181 & 29.5 & 1294 & 35.5 \\
\hline $120 \mathrm{~h}$ & 18.2 & 18.2 & 172 & 28.1 & 1412 & 35.1 \\
\hline $1600 \mathrm{~h}$ & 17.5 & 17.5 & 147 & 27.3 & 378 & 34.4 \\
\hline
\end{tabular}

The retention rate of tensile and bending strengths of the sample after UV aging were $96 \%$ and $104 \%$, respectively. The retention rate of tensile and bending strengths of the sample after high-temperature aging were $92 \%$ and $94 \%$, respectively. These results show that the short-term artificial aging test had little influence on the tensile and bending strengths of the sample.

The retention rate of elongation and impact strength of the samples after artificial aging are shown in Figure 5. The changes in elongation and impact strength were more pronounced than those in tensile and bending strengths. Within $504 \mathrm{~h}$ after the beginning of UV aging, the elongation of the sample slowly decreased to $90 \%$, decreased sharply afterward, reaches $20 \%$ in $768 \mathrm{~h}$, increased gradually to $60 \%$ in $1000 \mathrm{~h}$, and decreased slowly. The retention rate of impact strength in $504 \mathrm{~h}$ after the beginning of the aging test remained unchanged initially, began to rise, reached about $110 \%$ in $768 \mathrm{~h}$, and decline slowly afterward. In the beginning of the high-temperature aging test, the elongation of the sample decreased rapidly to about $30 \%$ at $16 \mathrm{~h}$. Then, it began to fluctuate up and down in $500 \mathrm{~h}$ down to the lowest and 
reached about 20\%. As shown in Figure 5(b), in the entire high-temperature aging test, the retention rate of the sample's impact strength was unchanged.

At the end of the UV aging test, the retention rate of elongation and impact strength of the sample were $52 \%$ and $92 \%$, respectively. After the high-temperature aging test, the retention rate of elongation and impact strength of the sample were $30 \%$ and $96 \%$, respectively.

This result was obtained because the elongation of the sample was susceptible to the internal stress or surface defects of the specimen and sensitive to changes in the structure of the specimen surface during the environmental adaptability test. Under the action of light, heat, oxygen, water and other environmental factors, the surface of the plastic material was easily damaged. The specimen's elongation was significantly reduced by the surface defects. Given that PP + EPDM is a toughened material, the EPDM and PP structures are similar and have good compatibility. Melt blending PP resin with EPDM and other elastomers can considerably increase PP toughness; thus, the short-term artificial aging on the impact strength of PP is not obvious [23].

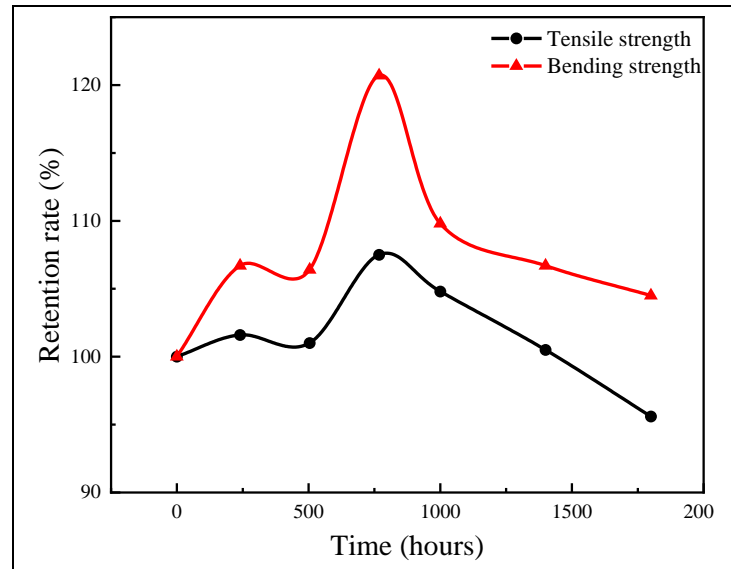

(a)

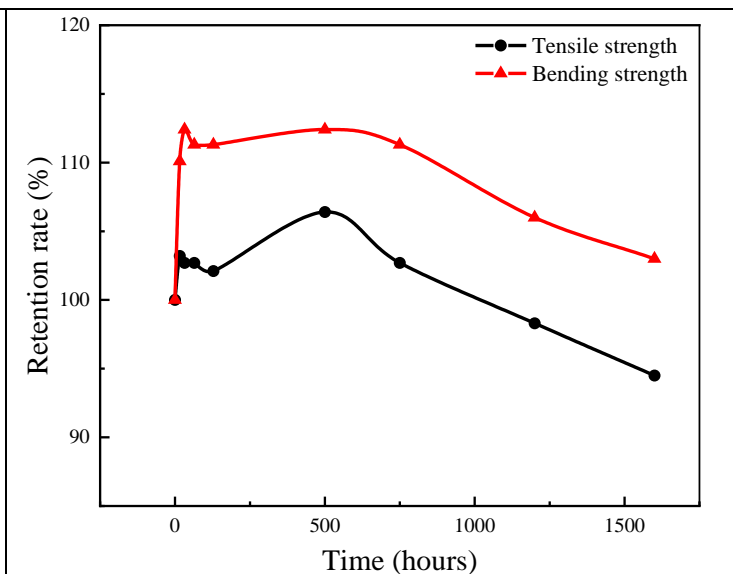

(b)

Figure 4. Retention of the tensile and bending strengths of the sample after artificial aging. (a) UV aging and (b) high-temperature aging

Compare the Figures 3, 4 and 5, it can be seen that the properties of PP under natural and artificial accelerated aging exhibited a significant difference. The change laws of mechanical properties in the artificial accelerated aging test and natural aging test were compared. The results showed that the UV aging test could simulate the change in the tensile and bending strengths of the bumper in the natural environment, and the correlation between the UV aging test and the tensile and bending strengths of the material under natural aging was strong.

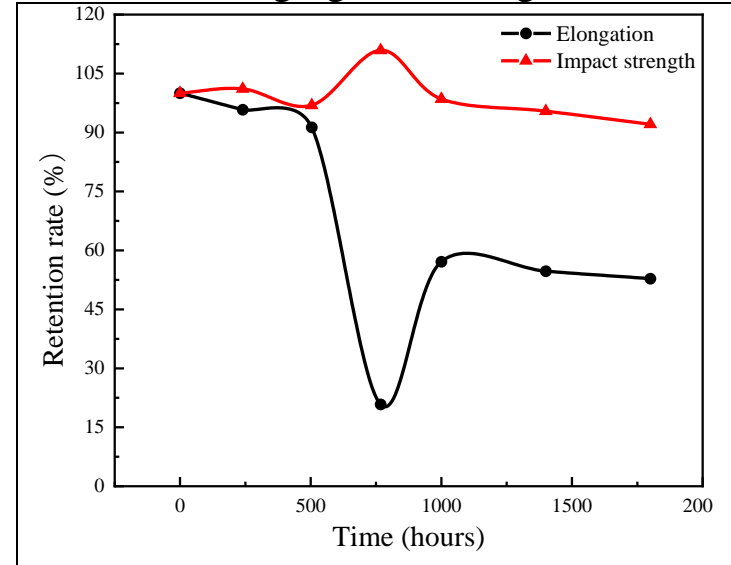

(a)

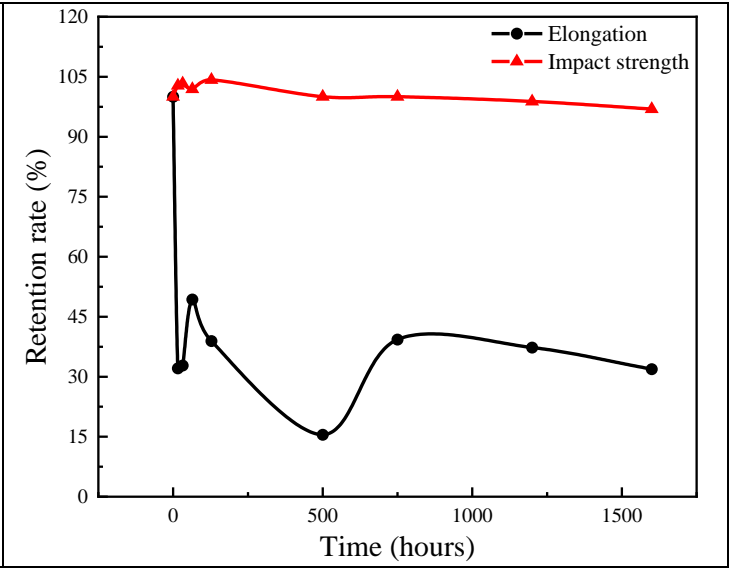

(b)

Figure 5. Retention of the elongation and impact strength of the sample after artificial aging. (a) UV aging and (b) high-temperature aging 
The elongation and impact strength of the materials in the artificial accelerated aging test were different from those in the natural aging test, indicating that the artificial accelerated aging test is unreliable method. Artificial accelerated aging tests do not fully reproduce the natural environmental conditions encountered by various materials. For example, the use of artificial light sources that are not consistent with the solar spectrum does not fully replicate the aging process of plastics in nature. Moreover, the natural aging raw materials in this study were prepared from market recycled car bumpers of different years. The deterioration of materials due to normal use is complex and more closely related to the natural environment in which they are used than to natural exposure testing. For example, openair parking accelerates the aging and oxidation of bumpers and other exterior parts. Parking in an underground garage protects bumpers from sunlight and rain; it effectively prevents the sun's UV rays from damaging the bumpers, thereby extending their service life.

\section{Conclusions}

Implementing an artificial acceleration aging test exerts a certain acceleration effect. This test can simulate the change law of the tensile and bending strengths of plastic materials for automobile bumpers in the natural chemical environment. The changes in the tensile and bending strengths of materials after a UV aging test are in line with those under natural aging; the tensile and bending strengths increase initially then decrease. This test provides a reference for the study of the aging performance of automotive polymers and a basis for the recycling of automotive polymers.

The tensile and bending strengths of materials have a good retention rate in natural and artificial accelerated aging, and elongation is sensitive to aging. In this study, the elongation of the materials under the two test methods showed a significant decrease, and the degree of change was greater than that for tensile and bending strengths. The impact strength of the material after UV aging was maintained at about $90 \%$, and the impact strength of the material after high-temperature aging was maintained at a rate close to $100 \%$. This result shows that the impact strengths of the material after artificial and natural aging were close to each other, but the difference after natural aging was larger. Thus, if we wish to further explore the change law of the impact strength of materials via an artificial aging test, we need to use a prolonged test time or adjust the artificial acceleration aging test conditions.

The internal structures of naturally and artificially aged PP will be investigated in future studies.

Acknowledgements. The authors express sincere thanks to the National Natural Science Foundation of China for financing this research within the project "Study on the mechanism of green high voltage electrostatic separation for ELV polymer particles"' under the label 52065034.

\section{References}

1.GODARA, S.S., NAGAR, S.N., Analysis of frontal bumper beam of automobile vehicle by using carbon fiber composite material. Materials Today: Proceedings, 2020, 26(Pt 2):2601-2607.

2.XIONG F, WANG DF, MA ZD, LV TT, JI LB. Lightweight optimization of the front end structure of an automobile body using entropy-based grey relational analysis. Proceedings of the Institution of Mechanical Engineers, Part D: Journal of Automobile Engineering, 2019, 233(4):917-934.

3.MITSCHANG, P., HILDEBRANDT, K., Polymer and composite moulding technologies for automotive applications. Advanced Materials in Automotive Engineering, 2012:210-229.

4.WANG GL, ZHAO GQ, ZHANG L, MU Y, PARK, C.P. Lightweight and tough nanocellular PP/PTFE nanocomposite foams with defect-free surfaces obtained using in situ nanofibrillation and nanocellular injection molding. Chemical Engineering Journal, 2018, 350:1-11.

5.BHASNEY, S.M., KUMAR, A., KATIYAR, V., Microcrystalline cellulose, polylactic acid and polypropylene biocomposites and its morphological, mechanical, thermal and rheological properties. Composites Part B, 2020, 184(Mar.1):107717.1-107717.15. 
6.LI TY, YU DL, ZHANG HS. Triboelectrostatic separation of polypropylene, polyurethane, and polyvinylchloride used in passenger vehicles. Waste Management, 2018, 73:54-61.

7.GABR, M.H., OKUMURA, W., UEDA, H., KURIYAMA, W., UZAWA, K., Mechanical and thermal properties of carbon fiber/polypropylene composite filled with nano-clay. Composites Part B: Engineering, 2015, 69:94-100.

8.PÉREZ, E., Alvarez, V., PÉREZ, C. J., BERNAL, C., A comparative study of the effect of different rigid fillers on the fracture and failure behavior of polypropylene based composites. Composites Part $\mathrm{B}$ Engineering, 2013, 52(Complete):72-83.

9.PÉREZ, E., FAMÀ, L., PARDO, S.G., ABAD, M.J., BERNAL, C., Tensile and fracture behaviour of PP/wood flour composites. Composites, 2012, 43B (7): 2795-2800.

10.SPIRIDON, I., LELUK, K., RESMERITA, A.M., DARIE, R.N., Evaluation of PLA-lignin bioplastics properties before and after accelerated weathering. Composites Part B Engineering, 2015, 69: 342-349.

11.STARK, N.M., MATUANA, L.M., Ultraviolet weathering of photostabilized wood-flour-filled highdensity polyethylene composites. Journal of Applied Polymer Science, 2003, 90(10):2609-2617.

12.OLIANI, W.L., FERMINO, D.M., LIMA, L., LUGAO, A., PARRA, D., Effects of accelerated thermal aging on polypropylene modified by irradiation process. Characterization of Minerals, Metals, and Materials 2015. John Wiley \& Sons, Ltd, 2015.

13.SOCCALINGAME, L., PERRIN, D., BENEZET, J.C., MANI, S., COIFFIER, F., RICHAUD, E., BERGERET, A., Reprocessing of artificial UV-weathered wood flour reinforced polypropylene composites. Polymer Degradation and Stability, 2015, 120(OCT.):313-327.

14.BEG, M.D.H., PICKERING, K.L., Accelerated weathering of unbleached and bleached Kraft wood fibre reinforced polypropylene composites. Polymer Degradation and Stability, 2008. 93(10):19391946.

15.AN, J., JEON, G.W., JEONG, Y.G., Preparation and properties of polypropylene nanocomposites reinforced with exfoliated graphene. Fibers and Polymers, 2012, 13(4):507-514.

16.SONG DD, GAO J, LI XG, LU L. Evaluation of aging behavior of polypropylene in natural environment by principal component analysis. Polymer Testing, 2014, 33:131-137.

17.FABIYI, J.S., MCDONALD, A.G., Degradation of polypropylene in naturally and artificially weathered plastic matrix composites. Maderas Ciencia Y Tecnología, 2014, 16(3): 275-290.

18.AZUMA, Y., TAKEDA, H., WATANABE, S., NAKATANI, H., Outdoor and accelerated weathering tests for polypropylene and polypropylene/talc composites: A comparative study of their weathering behavior. Polymer Degradation and Stability, 2009, 94(12):2267-2274.

19.BADJI, C., BEIGBEDER, J., GARAY, H., BERGERET, N., BENEZET, J.C., DESAUZIERS, V., Correlation between artificial and natural weathering of hemp fibers reinforced polypropylene biocomposites. Polymer Degradation and Stability,2018,148:117-131.

20.COLOM, X., CAÑAVATE, J., SUÑOL, J.J., PAGÉS, P., SAURINA, J., CARRASCO, F., Natural and artificial aging of polypropylene-polyethylene copolymers. Journal of Applied Polymer Science, 2003, 87(10):1685-1692.

21.ELMANOVICH, I.V., STAKHANOV, A.I., ZEFIROV, V.V., Thermal oxidation of polypropylene catalyzed by manganese oxide aerogel in oxygen-enriched supercritical carbon dioxide. Journal of Supercritical Fluids 2020, 158:104744.

22.FRANSEN, K., VERMOESEN, T., BEELAERT, G., MENTEN, J., HUTSE, V., WOUTERS, K., PLATTEAU, T., FLORENCE, E., Thermal degradation of polymeric materials. Additives for Polymers, 2005, 1994(3):10.

23.JAIN, A.K., NAGPAL, A.K., SINGHAL, R., GUPTA, N.K., Effect of dynamic crosslinking on impact strength and other mechanical properties of polypropylene/ethylene-propylene-diene rubber blends. Journal of Applied Polymer Science, 2000, 78(12):2089-2103.

Manuscript in received: 1.03 .2021 